\title{
Mosaic pancreas and type 3 diabetes
}

\author{
Beuy Joob • Viroj Wiwanitkit
}

Received: 16 January 2012 / Accepted: 19 December 2014 /Published online: 19 January 2015

(C) Research Society for Study of Diabetes in India 2015

Sir, the publication "Mosaic pancreas or type 3 diabetes: how do we define it?" is very interesting [1]. Irving et al. reported this interesting situation and proposed to name it as Mosaic Pancreas or type 3 diabetes [1]. The mentioned situation [1] is interesting and might be classified as a new kind of diabetes. However, the term type 3 diabetes is not a new one. This is already the specific medical term used for describing diabetes mellitus with Alzheimer's disease [2]. In brief, type 3 diabetes has already been well used for Alzheimer's disease which results in the insulin resistance in the brain for a long time. The idea that Alzheimer's might be type 3 diabetes was proposed by Dr. Suzanne De La Monte in 2005 [3]. Since then, over 20 papers have proposed this idea which is also accepted by clinicians $[2,4]$. The type of diabetes reported by Irving et al. is an atypical diabetes between type 1 and type 2 diabetes, which has nothing to do with the Alzheimer's disease. Hence, if Irving et al. would like to set a new classification, this situation should be named as "diabetes type 4."

\section{References}

1. Irving RR, Wright-Pascoe R, Mills JL, Choo-Kang EG, Mclaughlin WL, et al. Mosaic pancreas or type 3 diabetes: how do we define it? Int J Diabetes Dev Countr. 2011;31:133-7.

2. Wiwanitkit V. Diabetes type 3: a brief review. Diabetes Metabol Syndr Clin Res Rev. 2008;2:223-6.

3. de la Monte SM, Wands JR. Review of insulin and insulin-like growth factor expression, signaling, and malfunction in the central nervous system: relevance to Alzheimer's disease. J Alzheimers Dis. 2005;7(1):45-61.

4. de la Monte SM. Type 3 diabetes is sporadic Alzheimer s disease: Mini-review. Eur Neuropsychopharmacol. 2014 Jun 28. pii: S0924-977X(14)00176-X. doi: 10.1016/j.euroneuro. 2014.06.008.

B. Joob $(\bowtie)$

Sanitation 1 Medical Academic Center, Bangkok, Thailand

e-mail: beuyjoob@hotmail.com

V. Wiwanitkit

Wiwanitkit House, Bangkhae, Bangkok, Thailand 